\title{
Evaluating the Subgrade Reaction Modulus Variations with Soil Grains Shape in Coarse-Grained Soils Using Genetic Algorithm
}

\author{
Pouya Salari, Naser Hafezi Moghaddas*, Gholam Reza Lashkaripour, Mohammad Ghafoori \\ Faculty of Science, Ferdowsi University of Mashhad, Mashhad, Iran \\ Email: ${ }^{*}$ hafezi@um.ac.ir
}

How to cite this paper: Salari, P., Moghaddas, N.H., Lashkaripour, G.R. and Ghafoori, M. (2020) Evaluating the Subgrade Reaction Modulus Variations with Soil Grains Shape in Coarse-Grained Soils Using Genetic Algorithm. Open Journal of Geology, 10, 111-123.

https://doi.org/10.4236/ojg.2020.102006

Received: December 28, 2019

Accepted: January 17, 2020

Published: January 20, 2020

Copyright $\odot 2020$ by author(s) and Scientific Research Publishing Inc. This work is licensed under the Creative Commons Attribution International License (CC BY 4.0).

http://creativecommons.org/licenses/by/4.0/

\begin{abstract}
Subgrade reaction modulus (Ks) is one of the main factors in evaluating engineering properties of soils for structural calculations and operations. So, many studies have been performed on the effect of other soil geotechnical parameters on it. One is the effect of soil grains shape on engineering properties of soils, especially Ks. The aim of the present research is to evaluate the effect of soil grains shape on Ks for coarse-grained soils of the west of Mashhad, Iran. For this purpose, 20 PLTs were performed on coarse-grained soils of the west of Mashhad and Ks amounts were determined. Then, flakiness and elongation of the samples measured and changes of Ks by soil grain shape were evaluated. The results showed the strength dependency of Ks to grain forms which an increase in flakiness and elongation indices leads to a decrease in Ks. Therefore, it is necessary to reduce Ks estimated form empirical relationships for flaky and elongated soils. So, by writing a genetic algorithm-based program to find the optimal relationship between the grain shape and the subgrade reaction coefficient, a valid equation for correcting the results from previous empirical equations was presented.
\end{abstract}

\section{Keywords}

Subgrade Reaction Modulus (Ks), Flakiness Test, Elongation Test, Plate Load Test (PLT), Genetic Algorithm

\section{Introduction}

In granular soils, the overall geotechnical behavior is strongly affected by grain properties such as size, shape and crushability. Among the properties, grain shape has a considerable influence on the bulk of geotechnical properties [1] [2].

Particle shape description based on method of study (2D or 3D) can be classi- 
fied as flat, elongated, flaky, spherical, platy, elliptic and...

In coarse grain soil, size distribution and particle shape including sphericity, angularity and roughness have pivotal role in determining soil behavior [3]. Flakiness and elongation of particles directly affect permeability, strength, shear strength, residual resistance, elastic modulus and Ks of the coarse-grained soils. Ellipticity and plainness (as opposed to sphericity) promote inherent anisotropy and affect the evolution of stress-induced anisotropy. Plainness decreases stiffness and residual friction angle. Angularity and roughness promote a decrease in small-strain stiffness, an increase in high strain strength and affect the evolution of stress-induced anisotropy [4] [5] [6].

Ks is one of the most important soil engineering parameters which its accurate determination leads to optimization of construction operations. Ks is a conceptual relation between soil pressure and displacement, which has an important role in the calculation of the elements of strip and raft foundations and piles [7].

Equation (1) is used to calculate Ks:

$$
\mathrm{Ks}=\frac{q}{\delta}
$$

where $q$ is applied load and $\delta$ is the settlement rate caused by the applied load.

Recognizing the effect of grain shape on Ks not only can relate the soil geometrical parameters, which can be evaluated in the first step, with engineering properties but also it can present an accurate and initial recognition about the process of performing construction activities and calculations to optimize the construction operations.

Genetic algorithms are search and optimization algorithms based on the principles of natural evolution, which were first introduced by john Holland in 1970 [8]. Genetic algorithms also implement the optimization strategies by simulating evolution of species through natural selections.

Genetic algorithm is generally composed of two processes. First process is selection of individual for the production of next generation and second process is manipulation of the selected individual to form the next generation by crossover and mutation techniques [9]. The selection mechanism determines which individual are chosen for reproduction and how many offspring each selected individual produce. The main principle of selection strategy is the better is an individual; the higher is its chance of being parent.

Considering the influence of particle shape on soil engineering parameters such as $\mathrm{K}_{\mathrm{s}}$ and lack of practical relations for mentioned corrections, there is a need for accurate equation to determine real $\mathrm{K}_{\mathrm{s}}$ in flaky and elongated soils.

The present study focused on the evaluation of dependency of Ks values to grain shapes for coarse-grained sediments in the west of Mashhad. The coarsegrained sediments in the west of Mashhad originated from slate and phyllite metamorphic outcrops and contain a large percent of flaky grains that affect the soil properties as well as Ks [10]. 
In this paper, after some experiments, the optimal relation between the shape of the grains and Ks using genetic algorithm determined and an equation to correct the subgrade reaction coefficient in elongated and flaky soils proposed.

\section{Methodology}

Plate load tests performed in this article were based on regulations of the Ministry of Energy of Iran due to compliance of devices and availability of equipment. Also, flakiness and elongation tests, relative density $\left(D_{\mathrm{r}}\right)$, and in situ density (sand bottle test) were conducted according to American Society for Testing and Materials (ASTM) because of its validity and generality.

At first, by 20 plate load tests Ks amounts were calculated. Figure 1 shows the location of the test sites.

\subsection{Plate Load Tests Methods}

Table 1 shows several methods to carry out the Plate load tests [11]:

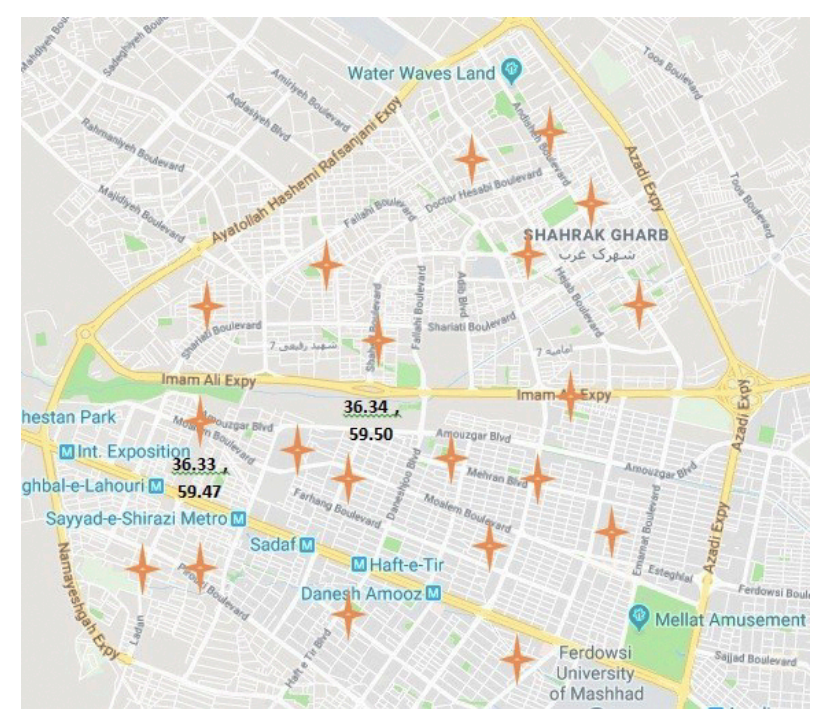

Figure 1. Location of the test sites (Google Earth).

Table 1. Plate load test methods.

1 The constant settlement rate: in this method, the settlement rate is selected based on soil penetrability coefficient and the size of the loading plate. As an approximate pattern, settlement rate can be considered to be $2.5 \mathrm{~mm} / \mathrm{min}$. This method is suitable for fine-grained cohesive soils.

2 Loading for creep: This method is used when the creep behavior of the soil is of interest or the structure is very sensitive to settlement.

3 Incremental loading: The final load is predicted as a multiple of allowable strength and loading stages are determined. In each loading stage, the settlement rate is measured in minutes $1,2,4$, and 8 . This method can be performed on all types of soil.

4 Cyclic Loading: This method can be used when the cyclic performance is considered. For example, in the airport and main road pavement, cyclic loading is performed to fix the settlement after applying the loading process several times.

5 Direct design loading: In this method, to consider the long-term behavior of the materials under foundation, the pressure applied to plate is selected by modeling the conditions of construction and operation of the structure. 
In the present study, incremental loading was used according to the type of soil and final goal.

To have more valid results, the PLTs were performed after removing surficial soil and placing and leveling the plates on the subsoil [12]. In addition to perform PLT with the power of $500 \mathrm{KN}$ jack and the circular rigid plate with diameter of $30 \mathrm{~cm}$, a loaded truck was used to apply the surcharge (Figure 2).

The device was calibrated by national standard organization with coverage factor $\mathrm{k}=2$ correspond to confidence level 95\%.

The required data were collected after installing equipment, applying load on a steel plate and recording load and settlement rate simultaneously by load and settlement gauges [13].

The loading process was incremental and its incremental steps were about one-fifth to one-fourth of the final estimated load.

The load was controlled in the desired increment and the next load increment was applied under the previous load after the settlement reached a stable state [14].

\subsection{Elongation and Flakiness Tests}

Then, the grains shape factors including elongation and flakiness coefficients of the grains of soil samples taken from each studied area were determined in the laboratory. According to the definitions, the flakiness coefficient is the weight percentage of grains that their thickness is less than 0.6 of mean grains size and elongation coefficient is the weight percentage of grains that their length are more than 1.8 of mean grains size [15]. It is of notes that mean grains size is the average mesh size of two continuous sieves that are used for aggregates gradation.

For this, first, two sieves size of 1 inch and 3/4 inch were used for sieving the studied samples. Then residual grains on $3 / 4$ inch sieve were weighted. The same process was done for sieves with sizes of $3 / 4$ inch and $1 / 2$ inch as well as $1 / 2$ inch and $3 / 8$ inch.

Then, in order to determine flakiness and elongation indices, the remained aggregates on $3 / 4$ inch, $1 / 2$ inch and $3 / 8$ inch sieves were passed through a wooden device with nails on it. The distance between two nails called specific distance, which means 1.8 times of the mean size of that soil group in gradation.

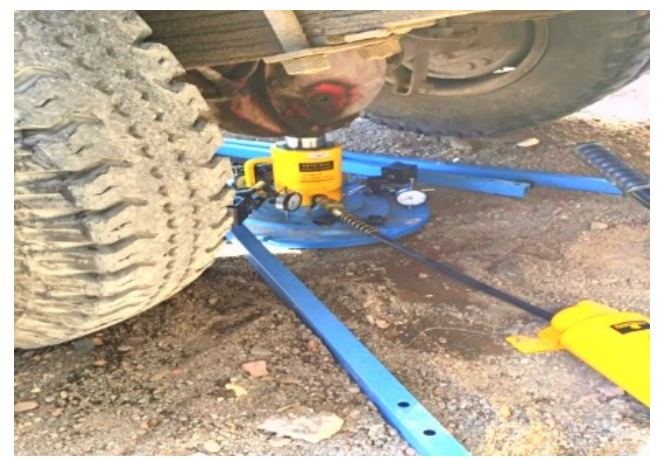

Figure 2. Plate load test. 
The elongation index is calculated by Equation (2) as follow:

$$
\text { elongation index }(\mathrm{EI})=\frac{\text { the weight of long grains }}{\text { overall weight of grains }} \times 100
$$

In the next step, the aggregate were re-mixed and passed through the grooves in the floor of a special metal frame and the weight of passed grains was calculated. The flakiness index is obtained by Equation (3) as follow:

$$
\text { flakiness index }(\mathrm{FI})=\frac{\text { the weight of passed grains through grooves }}{\text { overall weight of grains }} \times 100
$$

Figure 3 shows the tests.

Moreover, for each of the studied areas, in-situ density test was carried out by using sand bottle method and the dominant soil texture in the studied depth was determined [16]. Considering the effect of soil hardness on Ks and in order to determine only the effect of grain shape on this parameter, based on Equation 4 the amounts of $\gamma_{d}, \gamma_{d \min }$ and $\gamma_{d \max }$ were specified in the laboratory and relative density quantities were calculated [17].

$$
D_{r}=\frac{\gamma_{d}-\gamma_{d \min }}{\gamma_{d \max }-\gamma_{d \min }} \times \frac{\gamma_{d \max }}{\gamma_{d}}
$$

Then, a genetic algorithm based program in Matlab was written to calculate the actual subgrade reaction modulus (ks) values according to the grain shape.

\section{Results of Research}

The samples were taken from about $0.2 \mathrm{~m}-1 \mathrm{~m}$ depth that can be presumed as load effect limit and bears only $5 \%$ of surficial stress based on boussinesq studies by circularly load on the range of stress effect [7].

In spite of changing the soil properties in different directions due to the anisotropy of the soil, in order to the loading of the structure in the vertical direction, the subgrade reaction modulus is also calculated in this direction, Sampling and speculation were done in the same direction.

Table 2 presents the soil properties of 20 stations. As can be seen, the dominant

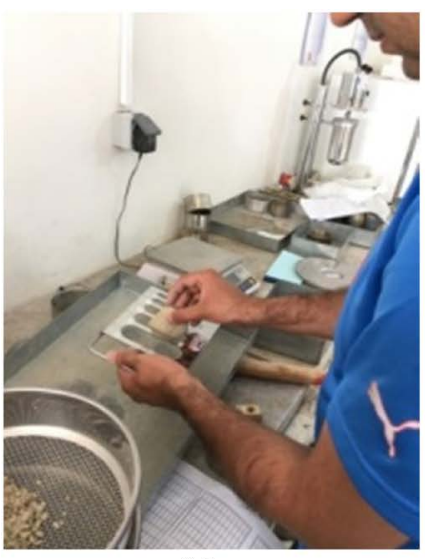

(a)

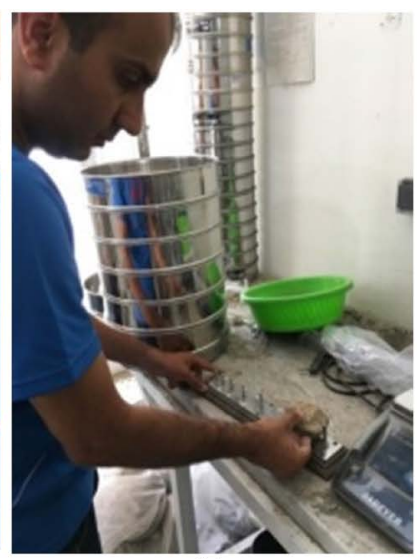

(b)

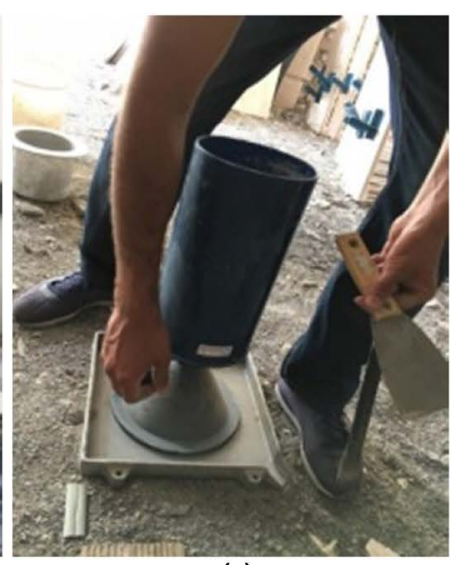

(c)

Figure 3. Tests steps and devices: (a) Flakiness test; (b) Elongation test; (c) Sand bottle method. 
Table 2. The properties of the studied soils.

\begin{tabular}{|c|c|c|c|c|c|c|c|c|c|c|c|}
\hline Station & $\begin{array}{c}\gamma_{d} \\
\left(\mathrm{gr} / \mathrm{cm}^{3}\right)\end{array}$ & 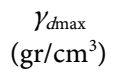 & $\underset{\substack{\left.\mathrm{gr}_{d \min } \\
\mathrm{cm}^{3}\right)}}{\gamma}$ & $D_{r}$ & Type & Station & $\begin{array}{c}\gamma_{d} \\
\left(\mathrm{gr} / \mathrm{cm}^{3}\right)\end{array}$ & $\underset{\left(\mathrm{gr} / \mathrm{cm}^{3}\right)}{\gamma_{d \max }}$ & $\underset{\left(\mathrm{gr} / \mathrm{cm}^{3}\right)}{\gamma_{d \min }}$ & $D_{r}$ & Type \\
\hline 1 & 1.81 & 1.84 & 1.78 & $50 \%$ & SW & 11 & 1.78 & 1.81 & 1.73 & $64 \%$ & GM \\
\hline 2 & 1.82 & 1.83 & 1.79 & $75 \%$ & SP & 12 & 1.81 & 1.84 & 1.79 & $40 \%$ & GW \\
\hline 3 & 1.77 & 1.78 & 1.75 & $67 \%$ & GC-GM & 13 & 1.79 & 1.82 & 1.74 & $64 \%$ & GP-GM \\
\hline 4 & 1.81 & 1.83 & 1.78 & $60 \%$ & SM & 14 & 1.80 & 1.82 & 1.77 & $61 \%$ & GP-GM \\
\hline 5 & 1.75 & 1.78 & 1.70 & $64 \%$ & SM & 15 & 1.76 & 1.78 & 1.73 & $61 \%$ & SM \\
\hline 6 & 1.81 & 1.82 & 1.79 & $68 \%$ & GC-GM & 16 & 1.77 & 1.84 & 1.75 & $23 \%$ & SP-SM \\
\hline 7 & 1.78 & 1.80 & 1.75 & $61 \%$ & GC-GM & 17 & 1.80 & 1.84 & 1.78 & $34 \%$ & GC-GM \\
\hline 8 & 1.80 & 1.82 & 1.77 & $60 \%$ & GP-GM & 18 & 1.79 & 1.82 & 1.73 & $67 \%$ & SP-SM \\
\hline 9 & 1.75 & 1.77 & 1.71 & $67 \%$ & SP-SM & 19 & 1.74 & 1.77 & 1.69 & $64 \%$ & SM \\
\hline 10 & 1.72 & 1.74 & 1.69 & $61 \%$ & SC & 20 & 1.80 & 1.82 & 1.78 & $50 \%$ & SM \\
\hline
\end{tabular}

texture of the soil is coarse-grained gravel and silty sand.

After performing PLTs and collecting the required data, by considering the following items, the Ks was calculated for each station using the pressure-settlement curve:

- Loading did not continue until the soil rupture.

- The amount of applied stress on plates and settlement were measured.

- Loading was performed on coarse-grained soils with low cohesion.

The amounts of Ks were calculated according to Wilun and Starzewski (1972) method [18].

This method is applied when the unloading is done before reaching the final strength of soil. In this process, equal intervals ( 3 to 4 intervals) are selected on the vertical line drawn on a pressure-settlement curve. Then, horizontal lines are drawn from the intervals to cross the curve. Next, vertical lines are drawn from the intersection point to cross the horizontal axis (pressure axis) and the lines with a $45^{\circ}$ angle are drawn from the intersection point of vertical lines and pressure axis to cross the adjacent vertical lines. Finally, from the obtained points, a direct line is drawn to intersect the pressure axis. This point shows the final strength of the soil (Figure 4).

For unsaturated soils such as studied samples, Equation (5) is used to calculate effective stress [19]:

$$
\delta^{\prime}=\left(\delta-u_{a}\right)+x\left(u_{a}-u_{w}\right)
$$

The difference $\delta-u_{a}$ is referred to the net normal stress, the difference $u_{a}-u_{w}$ is matric suction and the effective stress parameter $x$ is a material variable that is generally considered to vary between zero and unity.

Previous studies show low importance of suction in coarse-grained soils [20]. Due to the dominant texture of the soil (coarse-grained gravel and silty sand) in approximately dried studied soils, suction was not considered and $\delta^{\prime}=\delta$.

Table 3 presents the amounts of Ks for 20 studied points. 


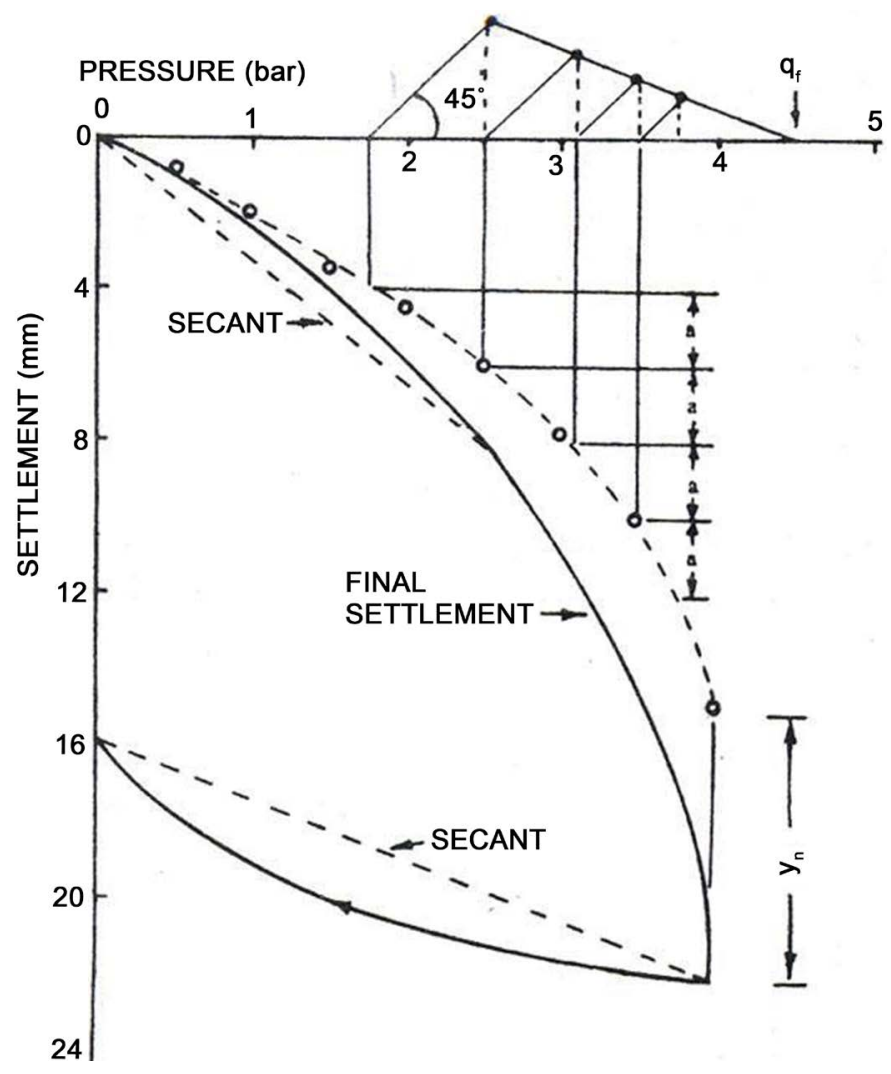

Figure 4. Determining the subgrade reaction modulus using the pressure-settlement curve (Wilun and Starzewski, 1972).

Table 3. Ks amounts for 20 points.

\begin{tabular}{cccc}
\hline Sample No. & $\mathrm{Ks}\left(\mathrm{kg} / \mathrm{cm}^{3}\right)$ & Sample No. & $\mathrm{Ks}\left(\mathrm{kg} / \mathrm{cm}^{3}\right)$ \\
\hline 1 & 7.2 & 11 & 8.2 \\
2 & 7.3 & 12 & 7 \\
3 & 7.6 & 13 & 7.9 \\
4 & 7.3 & 14 & 7.6 \\
5 & 6.4 & 15 & 8 \\
6 & 7.4 & 16 & 6.2 \\
7 & 7.6 & 17 & 6.3 \\
8 & 6.8 & 18 & 6.9 \\
9 & 8.5 & 19 & 7.1 \\
10 & 7.3 & 20 & 7.2 \\
\hline
\end{tabular}

After determining Ks, the flakiness and elongation coefficients of studied grains were calculated to find the relation between the Ks and soil grains shape (Table 4). Sieve $3 / 4$ in, $1 / 2$ in and $3 / 8$ in are sieves which their hole diameters are $20 \mathrm{~mm}, 12.5 \mathrm{~mm}$ and $10 \mathrm{~mm}$ respectively.

The higher elongation and flakiness indexes indicate that the soils under study are flaky and elongated. 
Table 4. The flakiness and elongation indexes of different sieves.

\begin{tabular}{|c|c|c|c|c|c|c|}
\hline \multirow{2}{*}{ Sample No. } & \multicolumn{2}{|c|}{$3 / 4$ in } & \multicolumn{2}{|c|}{$1 / 2$ in } & \multicolumn{2}{|c|}{$3 / 8$ in } \\
\hline & FI (\%) & EI (\%) & FI (\%) & EI (\%) & FI (\%) & EI (\%) \\
\hline 1 & 26 & 73 & 20 & 84 & 22 & 76 \\
\hline 2 & 40 & 83 & 24 & 73 & 25 & 81 \\
\hline 3 & 26 & 78 & 25 & 72 & 26 & 73 \\
\hline 4 & 28 & 78 & 29 & 78 & 26 & 82 \\
\hline 5 & 39 & 84 & 40 & 82 & 38 & 85 \\
\hline 6 & 22 & 81 & 25 & 75 & 28 & 70 \\
\hline 7 & 31 & 72 & 24 & 73 & 28 & 63 \\
\hline 8 & 26 & 85 & 42 & 82 & 45 & 79 \\
\hline 9 & 17 & 62 & 16 & 71 & 19 & 69 \\
\hline 10 & 25 & 85 & 20 & 71 & 33 & 74 \\
\hline 11 & 20 & 70 & 20 & 60 & 21 & 67 \\
\hline 12 & 24 & 83 & 28 & 77 & 35 & 80 \\
\hline 13 & 20 & 76 & 26 & 68 & 21 & 71 \\
\hline 14 & 20 & 79 & 21 & 72 & 24 & 70 \\
\hline 15 & 20 & 67 & 26 & 66 & 26 & 61 \\
\hline 16 & 32 & 90 & 37 & 87 & 44 & 81 \\
\hline 17 & 36 & 85 & 38 & 89 & 42 & 86 \\
\hline 18 & 28 & 90 & 35 & 81 & 36 & 82 \\
\hline 19 & 22 & 81 & 28 & 76 & 22 & 76 \\
\hline 20 & 23 & 82 & 28 & 63 & 28 & 74 \\
\hline
\end{tabular}

\section{Discussion}

Due to the effect of soil hardness on the subgrade reaction modulus and focus on the effect of soil elongation and flakiness on Ks, by calculating relative density values, statistical fittings were taken only on approximately similar relative density specimens, That is, 15 samples with a relative density between $60 \%$ and $75 \%$ and almost in the range of stiff soils [7] [21].

Figures 5-7 and Table 5 show the relationship of elongation and flakiness indexes with Ks. Generally, the results demonstrate the effectiveness of soil grain shape on Ks and an increase in elongation and flakiness indices leads to a reduction in Ks.

In Table 5, $\mathrm{R}^{2}$ indicates the degree of correlation between parameters and sig. amounts show if there is a relationship between parameters or not. Sig.2-tailed < 0.05 indicates that the variations of Ks by variables of elongation and flakiness indices are well justified [22]. The negative line slopes also show a reverse relation of elongation and flakiness indices with Ks [23].

As seen in Table 5, the lowest $R^{2}$ coefficient is for flakiness and Ks indices of 


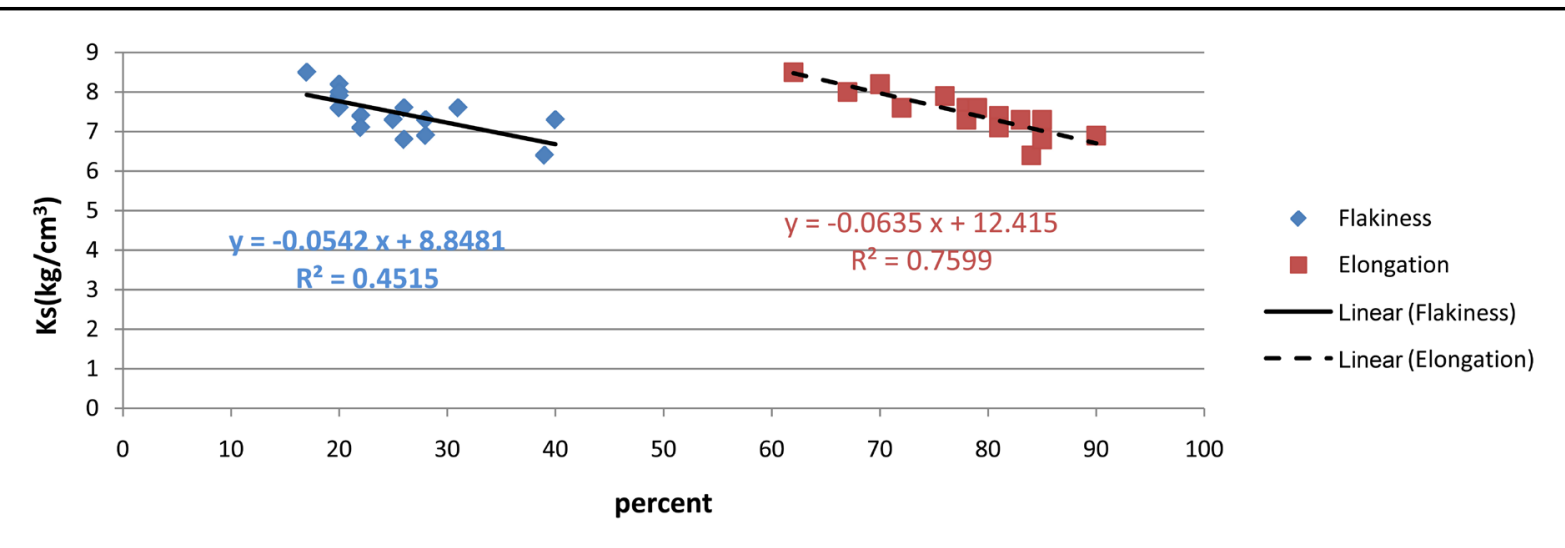

Figure 5. The relation of elongation and flakiness coefficients with Ks for $3 / 4$ in sieve.

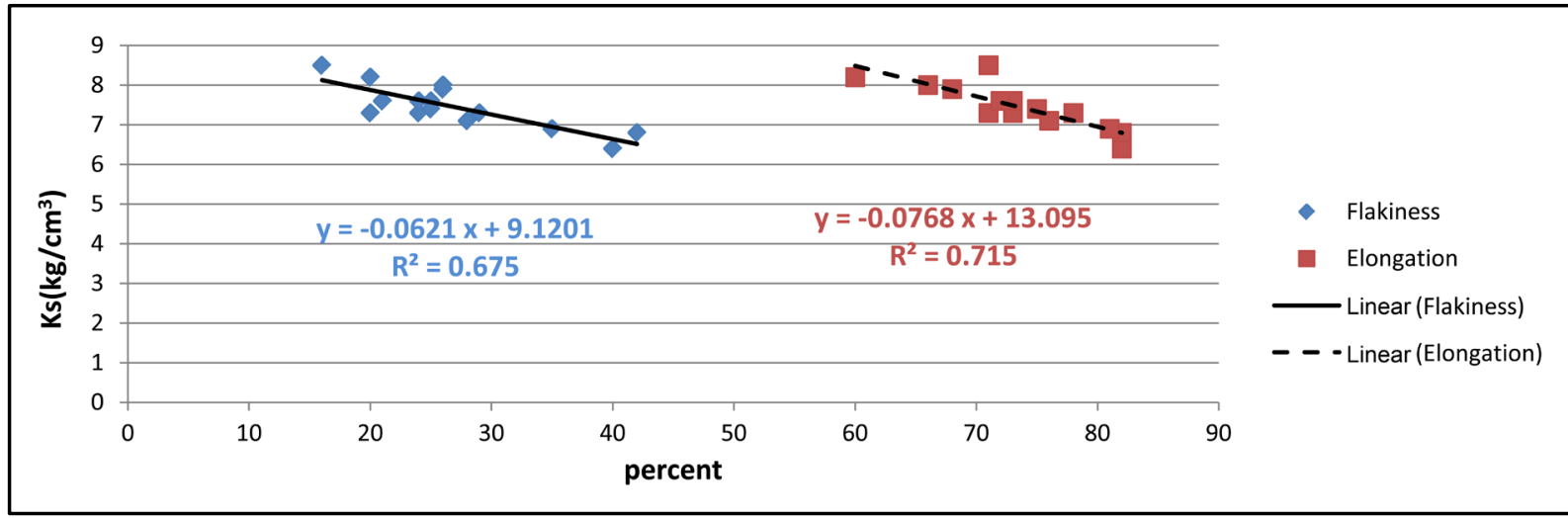

Figure 6. The relation of elongation and flakiness coefficients with Ks for $1 / 2$ in sieve.

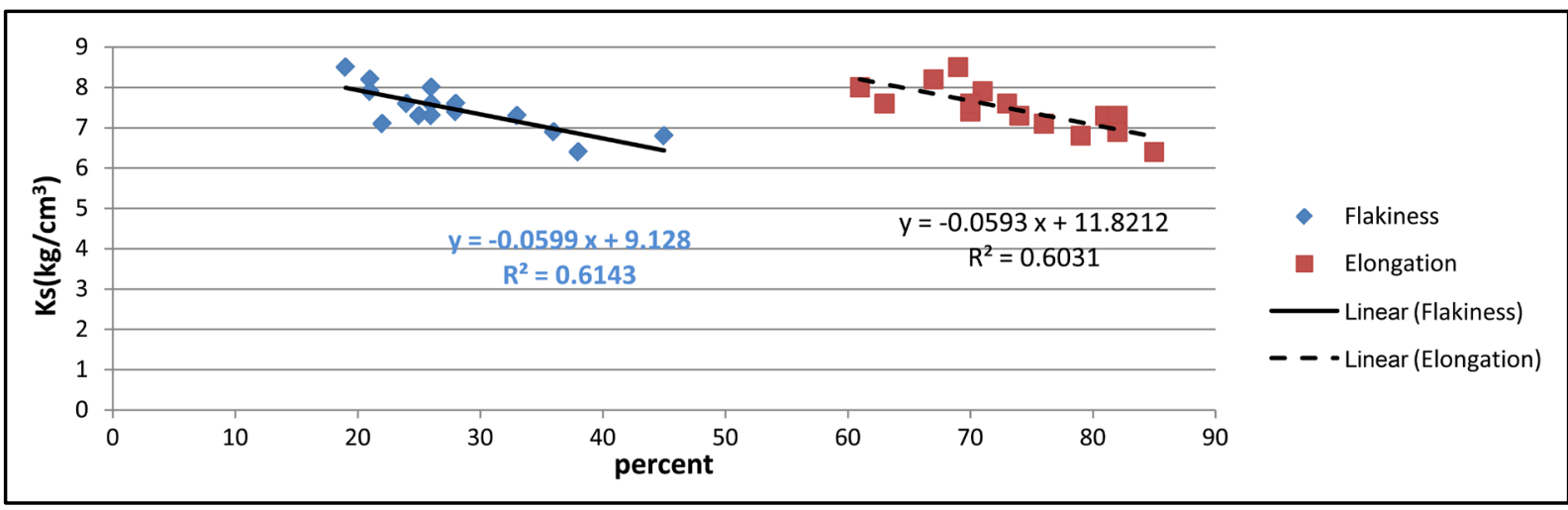

Figure 7. The relation of elongation and flakiness coefficients with Ks for $3 / 8$ in sieve.

Table 5. Correlation coefficients for different sieves.

\begin{tabular}{cccccccc}
\hline \multicolumn{8}{c}{ Correlations } \\
\hline & Elongation (3/4) & Flakiness (3/4) & Elongation (1/2) & Flakiness (1/2) & Elongation (3/8) & Flakiness (3/8) \\
\hline \multirow{2}{*}{ Ks } & Sig.2-tailed & 0.000 & 0.006 & 0.000 & 0.000 & 0.001 & 0.61 \\
& $\mathrm{~N}$ & 15 & 15 & 15 & 15 & 15 & 0.001 \\
& & & & 0.45 & 0.71 & 0.67 & 15 \\
\hline
\end{tabular}


$3 / 4$ inch sieve. It indicates more divergence relation of the flakiness of coarse grains with reduction of Ks in comparison with fine grains.

The gradient of lines in Figures 5-7 show that although the overall trend of reduction in Ks by increasing elongation and flakiness indices is almost the same in all figures, but the high elongation and flakiness of medium grains leads to more change in Ks compared to coarse and fine grains.

Finally, a genetic algorithm based program in Matlab was written to calculate real Ks values according to grain shape. Figure 8 shows the most optimal correlation between EI (average of three sieves), FI (average of three sieves) and Ks based on the fitted genetic algorithm.

In Figure 8, it can be seen that by $40 \%$ increase in elongation coefficients, about $20 \%$ reduction is observed in subgrade reaction modulus and the mentioned coefficients reach to almost $80 \%$ of their previous values. Although, doubling flakiness coefficients leads to $15 \%$ reduction in Ks.

Figure 9 shows the results of fitted genetic algorithm on in-situ and laboratory

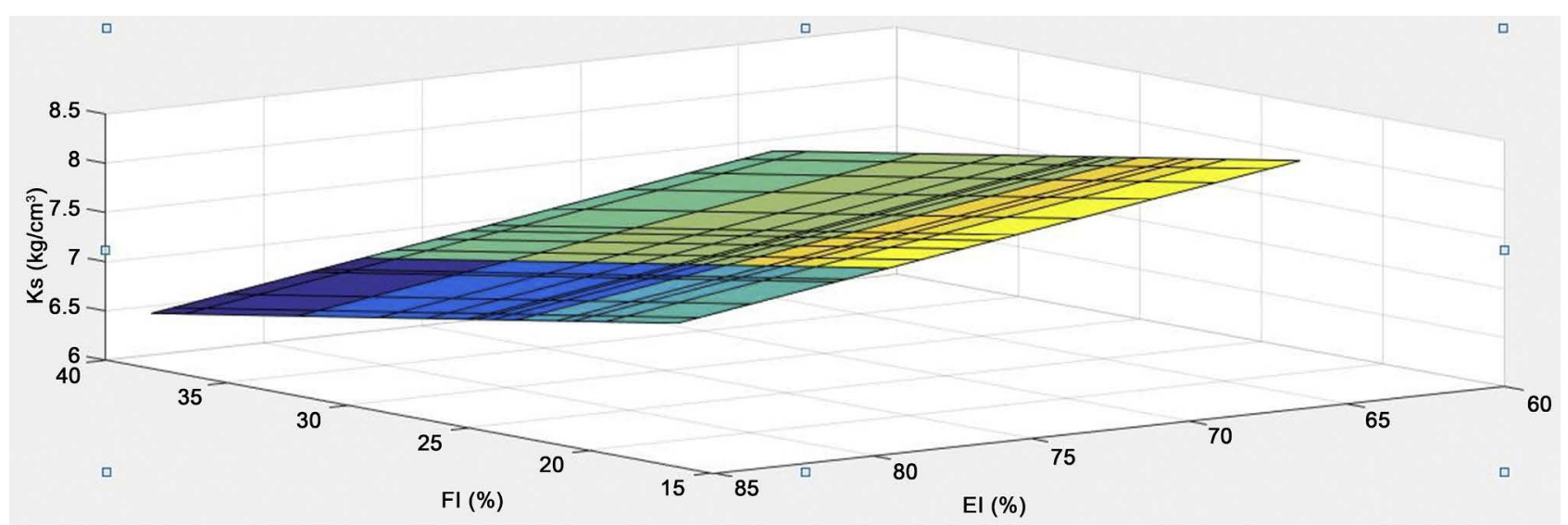

Figure 8. The relation between the elongation and flakiness coefficients with Ks.

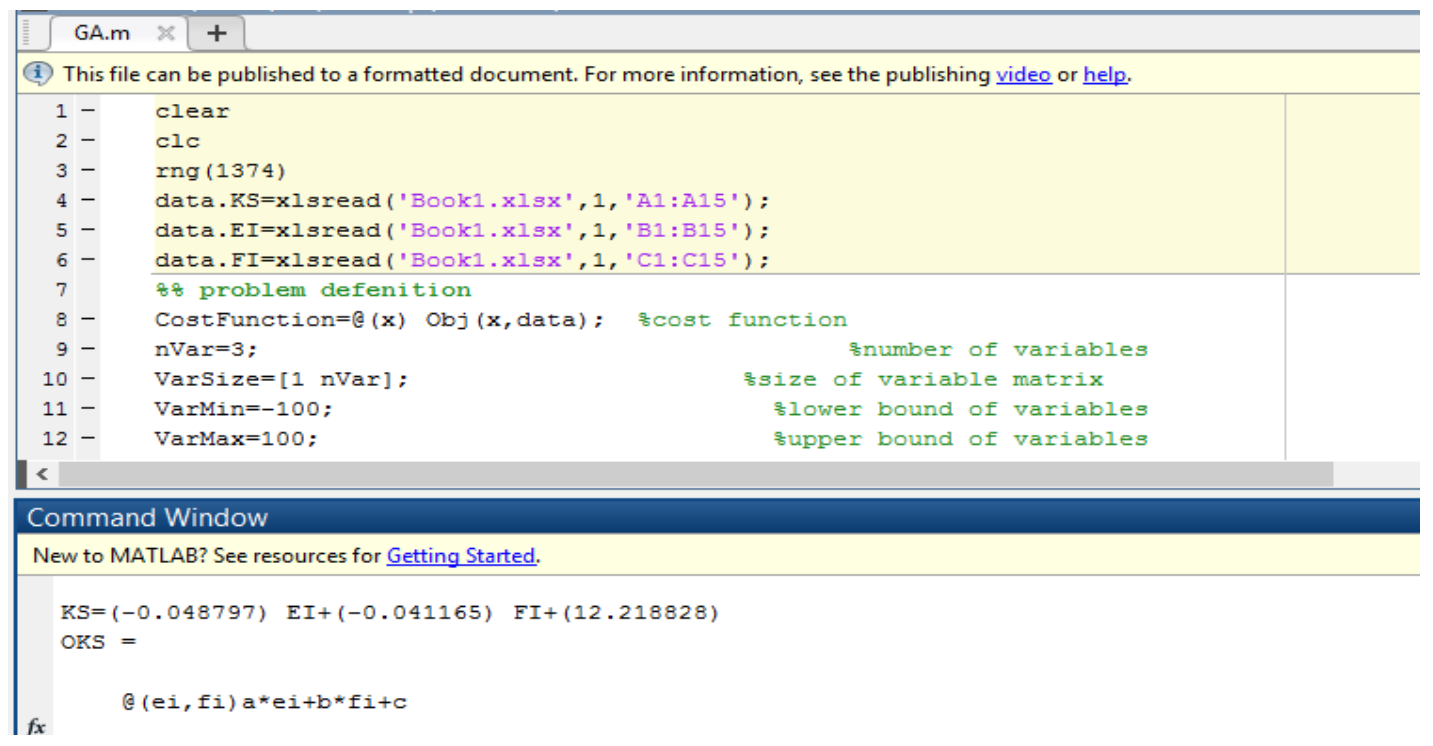

Figure 9. Fitted genetic algorithm results. 
experiments. Obtained coefficients (EI and FI coefficients) can be used to correct and reduce Ks amounts from empirical equations in flaky and elongated soils.

Due to implement tests on $30 \mathrm{~cm}$ diameter plate (The standard one), results generalizing can be done after correcting Ks obtained from empirical equations on $30 \mathrm{~cm}$ diameter foundation.

The following equation based on the genetic algorithm is used to correct the subgrade reaction modulus obtained from the previous equations for flaky and elongated samples in coarse-grained soils (Equation (6)).

$$
\mathrm{Ks}=(-0.0487) \mathrm{EI}+(-0.0411) \mathrm{FI}+12.2188
$$

As seen in Equation (6), 10\% increase in EI and FI leads to about $1 \mathrm{~kg} / \mathrm{cm}^{3}$ decrease in Ks values (based on tests on $30 \mathrm{~cm}$ plates).

\section{Conclusion}

The subgrade reaction modulus (Ks) is one of the most important elements in soil engineering to perform structural calculations. Perusing the effect of grain shape on Ks can present an accurate and initial recognition about the process of performing construction activities and calculations to optimize the construction operations. In the present research, 20 in-situ PLTs were conducted to determine Ks. Then elongation and flakiness tests were performed in laboratory and the effect of being elongated and flaky of soil particles and the shape of grains on Ks was analyzed. To take into account only the effect of soil elongation and flakiness on Ks, only 15 specimens in the range of stiff soils were fitted statistical correlations. The results showed that an increase in elongation and flakiness indices leads to a decrease in Ks. Finally, based on the results of this study, a genetic algorithm based program was written to calculate the real Ks for flaky and elongated coarse-grained soils for future geotechnical calculations. The results of tests and fitted genetic algorithm indicated that a two-fold increase in the average of flakiness coefficients results in about $15 \%$ reduction in Ks, which subsequently causes by $20 \%$ to $30 \%$ increase in elongation coefficient. The results of the present study shows that when empirical relationships are used for estimation of Ks for soils with elongated or flaky grains such as sediments of the west of Mashhad, it is necessary to make correction of Ks based on the FI and EI indexes in order to accurate structural calculations.

\section{Conflicts of Interest}

The authors declare no conflicts of interest regarding the publication of this paper.

\section{References}

[1] Cho, G.C., Dodds, J. and Santamarina, J.C. (2006) Particle Shape Effects on Packing Density, Stiffness and Strength: Natural and Crushed Sands. Journal of Geotechnical and Geoenvironmental Engineering, 132, 591-602. https://doi.org/10.1061/(ASCE)1090-0241(2006)132:5(591) 
[2] Chen, J.S., Chang, M.K. and Lin, K.Y. (2005) Influence of Coarse Aggregate Shape on the Strength of Asphalt Concrete Mixtures. Journal of the Eastern Asia Society for Transportation Studies, 6, 1062-1075.

[3] Li, Y.R. and Aydin, A. (2010) Behavior of Rounded Granular Materials in Direct Shear: Mechanisms and Quantification of Fluctuations. Engineering Geology, 115, 96-104. https://doi.org/10.1016/j.enggeo.2010.06.008

[4] Santamarina, J.C. and Cho, G.C. (2004) Soil Behavior: The Role of Particle Shape. Conference on Advances in Geotechnical Engineering, London, 29-31 March 2004, 604-617. https://doi.org/10.1061/40659(2003)2

[5] Yang, J. and Luo, X.D. (2015) Exploring the Relationship between Critical State and Particle Shape for Granular Materials. Journal of the Mechanics and Physics of Solids, 84, 196-213. https://doi.org/10.1016/j.jmps.2015.08.001

[6] Abdullahi, M. (2012) The Effect of Aggregate Type on Compressive Strength of Concrete. International Journal of Civil and Structural Engineering, 2, 791-800. https://doi.org/10.6088/ijcser.00202030008

[7] Das, B.M. (2011) Principles of Foundation Engineering. 7th Edition, Cengage Learning, Boston.

[8] Razali, N.M. and Geraghty, J. (2011) Genetic Algorithm Performance with Different Selection Strategies in Solving TSP. Proceedings of the World Congress on Engineering, Vol. 2, London, 6-8 July 2011.

[9] Lu, Y., Lu, S., Fotouhi, F., Deng, Y., Susan, D. and Brown, J. (2004) An Incremental Genetic K-Means Algorithm and Its Application in Gene Expression Data Analysis. BMC Bioinformatics, 5, 172. https://doi.org/10.1186/1471-2105-5-172

[10] Sokooti, R. (2015) Geotechnical Zoning and Geological Planning of the Campus of Ferdowsi University of Mashhad. Dissertation, Ferdowsi University of Mashhad, Mashhad.

[11] Water Resources Management Department of the Ministry of Energy (2005) PLTS on Soil and Soft Rock, Application, Method and Interpretation. Water Engineering Standard of Iran.

[12] Zhong, S.Q., Zhang, X.P. and Pan, H.L. (2005) Study on Foundation Soil Coefficient of Subgrade Reaction. Chinese Journal of Underground Space and Engineering, 7, 1109-1112.

[13] Barmenkova, E.V. and Matveeda, A.V. (2015) Calculation of Plates of Variable Rigidity on Elastic Foundation with Variable Coefficient of Subgrade Reaction. Procedia Engineering, 111, 97-102. https://doi.org/10.1016/j.proeng.2015.07.058

[14] Iancu, B.T. and Ionut, O.T. (2009) Numerical Analyses of Plate Loading Test. Buletinul Institutului Politehnic Din IASI Publicat de Universitatea Tehnica, Gheorghe Asachi, 55, 57-65.

[15] ASTM.D4791/10 (2010) Standard Test Method for Flat Particles, Elongated Particles, or Flat and Elongated Particles in Coarse Aggregate. ASTM International, West Conshohocken. https://doi.org/10.1520/D4791-19

[16] ASTM.D452400 (2006) Standard Test Methods for Minimum Index Density and Unit Weight of Soils and Calculation of Relative Density. ASTM International, West Conshohocken.

[17] ASTM.D1556/D1556M-15e1 (2015) Standard Test Method for Density and Unit Weight of Soil in Place by Sand-Cone Method. ASTM International, West Conshohocken. https://doi.org/10.1520/D1556_D1556M-15E01

[18] Mollahasani, A. (2008) Comparison of Soil Deformation Coefficient with In-Situ 
and Laboratory PLT. Dissertation, Ferdowsi University of Mashhad, Mashhad.

[19] Lu, N. and Likos, W.J. (2004) Unsaturated Soil Mechanics. John Wiley \& Sons, Inc., Hoboken, 30-45.

[20] Fredlund, D.G., Rahardjo, H. and Fredlund, M.D. (2012) Unsaturated Soil Mechanics in Engineering Practice. John Wiley \& Sons, Inc., Hoboken. https://doi.org/10.1002/9781118280492

[21] Bowels, J.E. (2001) Foundation Analysis and Design. 5th Edition, McGraw-Hill, New York, 7, 160-166.

[22] Winters, R., Winters, A. and Amedee, G.R. (2010) Statistics: A Brief Overview. Ochsner Journal, 10, 213-216.

[23] Isotalo, J. (2001) Basics of Statistics. University of Tampere, Tampere. 